\title{
IMPLICAÇÕES DA RECEPÇÃO DO APORTE DE CAPITAL NAS EMPRESAS ESTATAIS INDEPENDENTES: O CASO DO SERPRO
}

\section{IMPLICATIONS OF CAPITAL CONTRIBUTION RECEPTION TO INDEPENDENT STATE-OWNED COMPANIES: THE CASE OF SERPRO}

\author{
ORLANDO ALMEIDA SILVA \\ Auditor fiscal da Receita Federal do Brasil. Endereço: SHCS Quadra \\ 6, Bloco J, Lote 6/3, Ed. Camilo Cola, Asa Sul / 70297400 / Brasília/DF \\ | Brasil. \\ E-mail: orlando.silva@receita.fazenda.gov.br
}

\section{RODRIGO DE SOUZA GONÇALVES}

Doutor em Ciências Contábeis pelo Programa Multiinstitucional e Interregional de Pós-graduação em Ciências Contábeis (UnB/UFRN/UFPB). Professor do Departamento de Ciências Contábeis da Universidade de Brasília (UnB). Endereço: Campus Universitário Darcy Ribeiro, Asa Norte | 70910900 | Brasília/DF | Brasil.

E-mail: rgoncalves@unb.br

\section{MARIANA GUERRA}

Doutora em Administração pela Universidade de Brasília (UnB). Professora Adjunta do Departamento de Ciências Contábeis e Atuariais da Universidade de Brasília (DCCA/UnB) e Professora do Programa de Pós Graduação em Ciências Contábeis da Universidade de Brasília (PPGCONT/UnB). Endereço: Campus Universitário Darcy Ribeiro, Asa Norte | 70910900 | Brasília/DF / Brasil.

E-mail: guerra.mari@gmail.com

\section{RESUMO}

No estudo, avaliou-se a autossuficiência das atividades operacionais do Serviço Federal de Processamento de Dados (Serpro) na geração de caixa, de modo a permitir sua continuidade como empresa estatal independente ante o controlador. Para tanto, por meio de pesquisa de natureza qualitativa, do tipo descritiva e documental, analisou-se o comportamento dos fluxos de caixa das atividades operacionais, de investimento e de financiamento, em conjunto com as demonstrações contábeis, de 2005 a 2016. Observaram-se: decréscimo no saldo de caixa a partir de 2005, com recorrente insuficiência das atividades operacionais face ao consumo de caixa; recomposição do caixa mediante atividade de financiamento com constantes aportes de capital do ente controlador; indícios de pagamento de despesas correntes e dividendos com aporte de capital; recebimento financeiro em 2012 e 2014, sem perda da condição de independente, descumprindo normativos legais. A partir dos procedimentos adotados, constatou-se que, no período analisado, o Serpro encontrou-se em condições de não aderência às características e aos requisitos de estatal independente. Os resultados do estudo apresentam implicações práticas à medida que discute e propõe aspectos quanto ao planejamento e à execução das auditorias públicas voltadas à análise das condições de dependência das empresas estatais independentes sustentadas a partir das informações contábeis. 
Palavras-chave: Empresa estatal independente. Demonstração dos fluxos de caixa. Lei de Responsabilidade Fiscal.

\begin{abstract}
This paper addresses the self-sufficiency of the operational activities carried out for cash generation purposes at the Federal Data Processing Service (Serpro) aiming at its continuity as an independent state-owned company vis-à-vis the controlling shareholder. A qualitative, descriptive and documentary study is conducted to analyze the cash flow behaviors in operating, investment and financing activities, alongside the financial statements from 2005 to 2016. The analysis pointed to: a decrease in the cash balance from 2005 onwards, with a recurring shortage of operating activities compared to cash consumption; cash reconciliation based on financing activity involving constant capital injections from the controlling entity; evidence of payment of current expenses and dividends with capital contribution; receipt of financial contribution in 2012 and 2014, without prejudice to the status of independence and therefore in prejudice to legal regulations. The analysis also reveals that Serpro was uncompliant to the characteristics and the requirements of an independent state-owned company during the period. The results of this study have practical implications as it discusses and proposes aspects regarding the planning and development of the public audits oriented to the analysis of the conditions of dependence in independent state-owned companies building on the accounting information.
\end{abstract}

Keywords: Independent state-owned company. Cash flow statement. Fiscal Responsability Law.

\title{
1 INTRODUÇÃO
}

Nas empresas, de maneira geral, para financiar a aquisição dos recursos, os gestores dispõem de fontes geradoras de caixa operacional, de financiamento e de investimento. A escolha de uma delas, em caso de empresa saudável, deve considerar a melhor relação custo/benefício. Portanto, é de se esperar que, quanto melhor for o desempenho das atividades operacionais, maior será a autossuficiência, menos a empresa dependerá de recursos de terceiros - empréstimos/financiamentos - ou de aportes de capital dos sócios, como fonte financiadora dessas atividades ordinárias.

No setor público, a empresa dependente caracteriza-se, basicamente, por não conseguir ser autossustentável e sua continuidade demandar ação de seu controlador, ou seja, são empresas deficitárias que dependem de recursos do erário para financiar suas atividades ordinárias.

A necessidade de diferenciação conceitual entre empresa controlada pública dependente e independente dá-se em razão dos regimes jurídicos diferenciados a serem aplicados. Conforme preconizado no art. $165, \S 5^{\circ}$ e incisos da Constituição da República Federativa do Brasil (1988), as estatais independentes integram o Orçamento de Investimento, porque geram, ordinariamente, recursos suficientes para a sua manutenção, e, por essa razão, têm maior autonomia orçamentária, financeira e patrimonial. As dependentes integram os Orçamentos Fiscal e da Seguridade Social porque necessitam de recursos públicos para financiar a própria continuidade (Constituição da República Federativa do Brasil, 1988) e, por isso, observam toda a legislação aplicável às demais entidades da administração direta, a exemplo das emanadas pela Secretaria do Tesouro Nacional [STN] e pela Secretaria de Orçamento Federal [SOF], bem como se submetem à Lei n. 4.320 (1964), Lei Complementar n. 101(2000) e Lei n. 6.404 (1976).

Dentre as restrições fiscais descritas nos normativos ora mencionados, destacam-se: teto remuneratório da administração, geração de despesas, incluindo aquelas com pessoal e seguridade social, e ao endividamento, inclusive em relação à realização de operações de crédito. Apesar de a legislação apresentar tais restrições, não fica evidenciado, entretanto, a que tipo de déficit essa se refere - se ao econômico ou ao financeiro -, quando orienta que os recursos transferidos na forma de subvenção econômica destinam-se exclusivamente à 
cobertura de déficits de empresas e, portanto, devem ser alocados diretamente no orçamento da empresa beneficiária.

A despeito dessa lacuna, é possível observar no Orçamento Geral da União dos últimos anos uma quantidade crescente de dotação aportada nas empresas estatais independentes, destinada a aumento de capital. Dentre essas empresas, encontra-se o Serviço Federal de Processamento de Dados (Serpro), que, no período compreendido entre 2005 e 2014 recebeu quatro aportes para aumento de capital. Por outro lado, nesse mesmo período, a empresa apresentou acentuada redução nos estoques de caixa - de R $\$ 388$ milhões no fim de 2005 para R\$ 31 milhões no final de 2014; e, nos anos de 2006, 2008, 2009, 2010, 2011, 2013 e 2014 , déficits correntes líquidos de caixa, mesmo com os saldos alavancados pelos aportes ocorridos no período, suscitando possível indício de dependência da estatal.

Diante desse cenário, apresenta-se o seguinte problema: o Serpro atendeu aos requisitos legais e manteve as características necessárias de uma empresa estatal independente no período de 2005 a 2016? Para tanto, desenvolveu-se uma pesquisa com o objetivo de avaliar a autossuficiência das atividades operacionais do Serpro na geração de caixa, de modo a permitir a sua continuidade como empresa estatal independente face ao ente controlador no período de 2005 a 2016.

A presente pesquisa é relevante à medida que se propõe a fomentar a discussão acerca de uma temática ainda controversa no setor público brasileiro, que é a caracterização da perda de independência por empresas estatais. A referida discussão é oportuna sobretudo se analisada sob a perspectiva de que a persistência de uma entidade como independente, na condição de deficitária, sobrecarrega o Tesouro Nacional, ou seja, a sociedade de maneira geral. Além disso, possui implicações práticas ao contribuir para com o planejamento e a execução das auditorias públicas com escopo voltado à análise das condições de dependência das empresas estatais independentes, a partir das informações contábeis.

Adicionalmente, busca-se contribuir com a literatura sobre responsabilidade fiscal. Avança-se nessa temática quando se observa a abordagem de estudos anteriores (Gerigk, Clemente, \& Ribeiro, 2014; Linhares, Penna, \& Borges, 2013; Azevedo, 2013; Mello \& Dalchiavon, 2012; Santos \& Alves, 2011).

Por fim, o estudo avança nas reflexões acerca de a análise contábil fornecer o conhecimento do perfil econômico, financeiro e do desempenho operacional de entidade do setor público, com o propósito de reduzir a assimetria de informação entre a sociedade e a administração das empresas estatais.

\section{REFERENCIAL TEÓRICO}

\subsection{Empresas Estatais Dependentes e Independentes na Administração Pública}

As empresas estatais só podem ser criadas por meio de autorização legislativa, expedida caso a caso, e, no que tange a autonomia para execução de seu orçamento, dependerá do enquadramento acerca do seu nível de dependência de seu controlador.

A Lei Complementar n. 101 (2000), no inciso II do art. $2^{\circ}$, conceitua empresa controlada como aquela cujo capital social com direito a voto em sua maioria seja pertencente ao ente da Federação, enquanto que, no inciso III, conceitua a empresa estatal dependente como "empresa controlada que receba do ente controlador recursos financeiros para pagamento de despesas com pessoal ou de custeio em geral ou de capital, excluídos, no último caso, aqueles provenientes de aumento de participação acionária". Deduz-se do exposto que empresa estatal dependente é aquela que apresenta insuficiente geração de receitas para fazer face às despesas correntes, necessitando de aportes de recursos orçamentário/financeiro do Tesouro Nacional, situação que a coloca sob a abrangência da Lei Complementar n. 101, ao contrário das empresas estatais independentes.

Detalhando mais o conceito, o inciso II, do art. $2^{\circ}$ da Resolução do Senado Federal $n$. 43 (2001), menciona, além daqueles já descritos, o fato de a empresa, tendo recebido recurso financeiro no exercício imediatamente anterior, possuir no exercício corrente "autorização orçamentária na Lei Orçamentária Anual [LOA] para recebimento de recursos financeiros com 
idêntica finalidade". Percebe-se, à luz da referida Resolução, a necessidade de que tenha ocorrido o pagamento de despesas com pessoal, de custeio em geral ou de capital no exercício anterior, com previsão orçamentária no exercício corrente para recebimento de recursos financeiros com idêntica finalidade. Então, uma única transferência, ou transferências esporádicas, por essa Resolução, não é suficiente para caracterizar a perda da independência. Para caracterizar a dependência, faz-se necessário a combinação de recebimento de recurso financeiro no ano anterior mais previsão orçamentária no exercício corrente.

Essa regra pode dificultar a descaracterização da condição de independência gozada por uma empresa pública ou de economia mista, dado que o repasse financeiro pode se dar de uma só vez, mas em volume vultoso o suficiente para beneficiar mais de um exercício, distanciando-se, assim, da nova autorização orçamentária. Desse modo, a suposta empresa, do ponto de vista formal, vai continuar independente, mas, em essência, os recursos anteriormente recepcionados financiam a continuidade.

Adicionalmente, a Portaria STN n. 589 (2001), em seu art. $3^{\circ} \S$ único, combinado com o art. $7^{\circ}$ da Portaria Interministerial STN/SOF n. 163 (2001), orienta que os recursos transferidos na forma de subvenção econômica destinam-se exclusivamente à cobertura de déficits de empresas e, portanto, devem ser alocados diretamente no orçamento da empresa beneficiária. A partir desses referidos normativos legais, a empresa estatal que estiver em déficit e, ainda nesse estágio, receber recursos públicos, esse valor será classificado como uma subvenção econômica e a empresa beneficiária integrará o Orçamento Fiscal, como uma unidade desse orçamento, ou seja, o déficit caracteriza a perda da independência, migrando a empresa do Orçamento de Investimento para o Orçamento Fiscal.

Ainda com relação a transferências de recursos públicos para empresas em situação de déficit, o art. 167, VIII, da Constituição da República Federativa do Brasil (1988), exige autorização legislativa específica quando da utilização de recursos do Orçamento Fiscal e da Seguridade Social para cobrir déficit de empresas. Em que pese a citação do déficit nas duas normas (Portaria STN n. 589, 2001 e Portaria Interministerial STN/SOF n. 163, 2001), cabe destacar que a legislação não apresenta os meios para sua caracterização. No presente estudo, fez-se uma escolha metodológica para suprir tal lacuna (ver seção 2.2).

Essa escolha metodológica busca reunir as condições que permitam caracterizar uma empresa estatal como dependente, quais sejam: (1) identificar se há previsão de despesa nos Orçamentos Fiscal e da Seguridade Social; (2) mesmo integrando o Orçamento de Investimento, identificar se apresenta-se deficitária ao receber recurso do ente controlador situação que a fará migrar para os Orçamentos Fiscal e da Seguridade Social, perdendo a independência; (3) identificar se no Orçamento de Investimento, mesmo não sendo deficitária, recebe aportes financeiros do controlador destinados ao pagamento de pessoal, ao custeio ou ao pagamento de despesas de capital (exceto para aumento da participação acionária) no exercício anterior, com previsão orçamentária idêntica para o exercício seguinte.

\subsection{Avaliação da Situação Financeira por Meio da Análise dos Fluxos de Caixa}

Estudos recentes relativos à avaliação da situação econômico-financeira de empresas, no Brasil e no exterior, tais como os de Sun, Ding, Guo e Li (2016) e Mamede, Nakamura, , Nakamura, Jones, \& Jardim (2017), têm se concentrado em tópicos das finanças corporativas, cujo principal objetivo é analisar a estrutura de capital das empresas. A contribuição prática desses trabalhos é a de apresentar o que seria uma adequada estrutura de capital para os gestores financeiros das instituições, seja privada e/ou estatal, contribuindo para um menor nível de custo de capital (Aslan \& Kumar, 2012; Nisiyama \& Nakamura, 2015).

Há ainda trabalhos interessados em finanças públicas, discutindo o controle do endividamento dos entes federativos, e a lógica e/ou processo orçamentário em diferentes níveis (e.g., Andrade, 2012; Hatadani, 2015; Azevedo, 2016). O presente trabalho, entretanto, tem interesse na gestão de caixa de uma empresa estatal, discutindo especificamente déficit financeiro como evidência de dependência do ente controlador.

Segundo Fernandes e Meireles (2013), a autonomia financeira de uma empresa pode ser entendida como a capacidade de autoprover recursos financeiros para enfrentar 
contratempos operacionais. A situação financeira (deficitária ou superavitária) seria, portanto, decorrente dessa capacidade/autonomia.

Como discutido na seção 2.1, a legislação não define qual o tipo de déficit - se econômico ou financeiro - em que a empresa deve estar para que o aporte seja considerado uma subvenção e necessite de autorização legislativa específica para a transferência do recurso, bem como não elegeu a metodologia para o cálculo desse déficit. A utilização do conceito de déficit financeiro, calculado por meio das informações constantes na Demonstração dos Fluxos de Caixa (DFC), divulgada em conformidade com o Pronunciamento Técnico 03 do Comitê de Pronunciamentos Contábeis [CPC] - PT CPC 03 (CPC, 2010), para análise de indícios de perda ou não de independência no presente trabalho, apresenta-se como uma escolha conservadora, se comparado ao déficit econômico.

Segundo Braga e Marques (2001), diversos indicadores de desempenho financeiro podem ser obtidos a partir da DFC, notadamente aqueles relativos ao fluxo de caixa gerado (ou consumido) pelas atividades operacionais normais da companhia. Em consonância, para Quintana, Porto e Lemos (2008), a DFC possui relevância por evidenciar, para usuários internos e externos, como ocorre a gestão do caixa, em outras palavras, como a empresa gerencia o recurso disponível em determinado período, demonstrando sua origem e aplicação, além da capacidade de a empresa honrar seus compromissos no curto prazo. Assim, índices obtidos a partir das informações dessa demonstração, tal qual os propostos por Braga e Marques (2001), podem auxiliar analistas, credores e demais stakeholders na previsão de fluxos futuros de caixa e na avaliação de desempenho dos fluxos correntes, constituindo-se em instrumento de acompanhamento do desempenho financeiro (Bachmann, Tonin, Colauto, \& Scherer, 2014).

Por meio da DFC, seria possível, portanto, verificar: (a) a capacidade da empresa gerar futuros fluxos líquidos positivos de caixa; (b) a capacidade de a empresa honrar seus compromissos, pagar dividendos e os empréstimos obtidos; (c) a liquidez, solvência e situação financeira da empresa; (d) a taxa de conversão de lucros em caixa; (e) comparar o desempenho operacional de diferentes empresas, por eliminar os efeitos de distintos tratamentos contábeis para as mesmas transações e eventos, dentre outros (Braga \& Marques, 2001). Em outras palavras, a utilização de indicadores obtidos por meio da DFC facilita a interpretação da situação financeira (mais especificamente, no presente estudo, do déficit financeiro) da empresa, destacada, portanto, a relevância desses indicadores se comparados aos convencionais de estrutura, lucratividade e retorno obtidos a partir do Balanço Patrimonial, por exemplo.

Braga e Marques (2001), especificamente, apresentaram os seguintes grupos de índices financeiros que podem ser obtidos por meio das informações divulgadas na DFC: (i) Quocientes de Cobertura de Caixa; (ii) Quocientes de Dispêndio de Capital; (iii) Índices de Retorno do Fluxo de Caixa e (iv) Quocientes de Qualidade do Resultado. O trabalho desses autores centrou-se na exemplificação desses índices na Companhia Vale do Rio Doce e nas Centrais Elétricas de Minas Gerais (CEMIG). No presente estudo, amplia-se a aplicação dos referidos índices, juntamente com a proposta de Almeida (2000) (ver seção 4).

\section{METODOLOGIA}

O estudo desenvolvido é de natureza qualitativa, do tipo descritiva e documental, com foco no caso Serpro. Desenvolveram-se análises horizontal e por indicadores, a partir das informações obtidas por meio das demonstrações financeiras da empresa estudada, no período de 2005 a 2013, haja vista que o Serpro passou a publicar tal demonstrativo somente a partir de 2005.

De maneira mais específica, para avaliar a situação financeira do Serpro, inicialmente foi realizada a análise horizontal dos saldos de caixa e dos fluxos de caixa das atividades operacionais (FCO), de investimento ( $F C l)$ e financiamento (FCF). O cálculo da variação horizontal teve como base o ano imediatamente anterior. Logo, 2005 será base comparativa apenas para 2006, e, assim, sucessivamente. 
Almeida (2000) apresenta um quadro comparativo (Tabela 1), por meio do qual, mediante a análise dos fluxos de caixa, é possível classificar os estágios em que se encontra uma organização. Ressalta-se, contudo, que a análise deve ser feita em conjunto com outros indicadores para confirmar ou não as tendências observadas. Para tanto, no segundo momento, calcularam-se os indicadores listados na Tabela 2, tendo como referência Braga e Marques (2001) e Almeida (2000).

Tabela 1

\section{Estágios da organização}

\begin{tabular}{l|c|c|c|c}
\hline Fluxo de caixa/Estágio & Início & Expansão & Maturidade & Declínio \\
\hline Operacional - FCO & - & + & ++ & + \\
\hline Investimento - FCl & -- & - & - & + \\
\hline Financiamento - FCF & ++ & + & - & - \\
\hline
\end{tabular}

Nota. Fonte: Almeida (2000)

Em resumo, as informações do Quadro 1 podem ser interpretadas a partir do ciclo de desenvolvimento da organização. No início, há um maior aporte de recursos para fazer frente aos investimentos de natureza permanente e, para tanto, a tendência é a de que o fluxo de caixa operacional (FCO) seja negativo. $\mathrm{Na}$ fase de expansão, espera-se que o FCO seja positivo, contudo, ainda com a necessidade de captação de recursos frente aos investimentos necessários. Na fase de maturidade, a organização apresenta uma maior entrada de recursos via $\mathrm{FCO}$ e, na mesma medida, há o pagamento dos recursos captados e pagamento de dividendos, via fluxo de caixa de financiamento (FCF) negativo. Por fim, na fase de declínio, espera-se ainda um FCO positivo, pela redução dos recebíveis e estoques. Porém, em razão da desmobilização, o fluxo de caixa de investimentos $(\mathrm{FCl})$ passa a ser positivo. A seguir é apresentada a Tabela 2 a qual sintetiza os indicadores utilizados no presente estudo.

Tabela 2

Indicadores para análise desempenho a partir da DFC

\begin{tabular}{l|l}
\hline Indicador/fórmula & Índices face ao objetivo da pesquisa \\
\hline
\end{tabular}

\begin{tabular}{|c|c|}
\hline $\begin{array}{l}\text { Cobertura de dívidas com caixa = } \\
\text { (FCO -dividendo }) \div \text { exigível }\end{array}$ & $\begin{array}{l}\text { Objetiva avaliar a capacidade de o Serpro honrar suas obrigações, } \\
\text { somente com o caixa livre gerado pelo negócio da empresa. O índice } \\
\text { auxilia as instituições na avaliação da capacidade da entidade honrar } \\
\text { suas obrigações, com caixa gerado das operações, para cobrir as } \\
\text { dívidas existentes. }\end{array}$ \\
\hline $\begin{array}{l}\text { Cobertura de dividendos com caixa = } \\
\text { FCO } \div \text { dividendos totais e juros sobre } \\
\text { capital próprio }\end{array}$ & $\begin{array}{l}\text { Fornece evidência da capacidade de o Serpro pagar dividendos e } \\
\text { juros sobre capital próprio atuais com base no fluxo de FCO. }\end{array}$ \\
\hline $\begin{array}{l}\text { Qualidade do resultado }=\mathrm{FCO} \div \text { lucro } \\
\text { antes do juros e impostos }\end{array}$ & $\begin{array}{l}\text { Com esse índice buscam-se as seguintes evidências para o estudo: } \\
\text { (i) indicar o que o resultado operacional gerou de caixa operacional; } \\
\text { (ii) fornecer uma indicação da dispersão entre os fluxos de caixa } \\
\text { operacional e os lucros operacionais divulgados pelo Serpro. }\end{array}$ \\
\hline $\begin{array}{l}\text { Investimento/financiamento }=\mathrm{FCl} \div \\
\text { FCF }\end{array}$ & $\begin{array}{l}\text { Compara os fluxos líquidos do Serpro necessários para finalidade de } \\
\text { investimento, com aqueles gerados de financiamentos. }\end{array}$ \\
\hline $\begin{array}{l}\text { Cobertura dos investimentos }=\mathrm{FCO} \div \\
\text { FCl }\end{array}$ & $\begin{array}{l}\text { Avalia a capacidade de o Serpro financiar seus investimentos com } \\
\text { recursos gerados no negócio da empresa. }\end{array}$ \\
\hline Retorno Total & $\begin{array}{l}\text { Mede o nível de geração interna de recurso no Serpro para aplicação } \\
\text { nas suas atividades de investimento e financiamento. }\end{array}$ \\
\hline $\begin{array}{l}\text { Retorno sobre o Lucro = FCO } \div \text { Lucro } \\
\text { Líquido do exercício }\end{array}$ & $\begin{array}{l}\text { quanto do lucro líquido do Serpro foi realizado financeiramente. } \\
\text { orno do lucro líquido em termo de caixa. }\end{array}$ \\
\hline $\begin{array}{l}\text { Retorno do caixa sobre os ativos = } \\
\text { FCO antes de juros e impostos } \div \text { ativos } \\
\text { totais }\end{array}$ & $\begin{array}{l}\text { O valor de caixa gerado pelas operações do Serpro para cada } \\
\text { unidade monetária do ativo aplicado. }\end{array}$ \\
\hline $\begin{array}{l}\text { Ret } \\
\text { FCC }\end{array}$ & ixa dos \\
\hline
\end{tabular}

Nota. Fonte: Braga, R., \& Marques, J. A. V. D. C. (2001). Avaliação da liquidez das empresas através da análise da demonstração de fluxos de caixa. Revista Contabilidade \& Finanças, 12(25), 06-23.

Sobre os indicadores, cabe esclarecer que, com relação ao índice de retorno do caixa sobre os ativos, no presente estudo, fez-se uma adaptação para que se contemplasse somente os ativos imobilizados e intangíveis, tendo vista que esses itens foram os mais representativos 
no consumo de recursos financeiros. Optou-se por não utilizar o índice de financiamento dos investimentos, por entender que somente o índice de cobertura dos investimentos é suficiente para o propósito deste trabalho. Além disso, para o cálculo dos indicadores: (a) o conceito de juros utilizado nas fórmulas foi o de "resultado financeiro", que é a soma das receitas financeiras menos os juros do exercício, informados na Demonstração do Resultado do Exercício; (b) o conceito de dividendos utilizado foi o de dividendos mais os juros sobre capital próprio; (c) o $\mathrm{FCl}$ foi convertido em positivo para possibilitar a análise dos índices de financiamento e investimentos e (d) o FCF e FCl foram convertidos em positivo para possibilitar a análise do índice retorno total.

Assim, a análise horizontal possibilitou a comparação de elementos homogêneos de sucessivos períodos - caixa com caixa -, ou seja, uma avaliação em perspectiva do fluxo de caixa. Complementarmente, a análise dos indicadores possibilitou a comparação de itens do fluxo de caixa com elementos de outros demonstrativos, quais sejam: Notas Explicativas, das Leis Orçamentárias e dos Decretos de autorização de aumento de capital sobre recorrentes recepções de aportes para aumento de capital no Serpro.

Considerando os objetivos do trabalho, os dados foram analisados de forma nominal, sem deflacioná-los, e, portanto, constitui-se uma limitação aos resultados. Ainda, o estudo foi realizado com uma só empresa estatal dependente. Outra limitação está no fato de este trabalho ter sido desenvolvido sob a ótica do usuário externo, alheio ao processo de elaboração dos demonstrativos financeiros na forma de fonte primária. $\mathrm{E}$, somente com essa ótica, não foi possível identificar referência a planos de expansão ou orçamento de projetos que demandem aportes específicos.

\section{ANÁLISE DOS RESULTADOS}

Conforme consta do Relatório de Gestão, o Serpro foi criado pela Lei n. 4.516 (1964) e está disposto sobre a Lei n. 5.615 (1970), sob a forma de empresa pública com capital integralmente da União. A partir do ano de 2004, o Serpro migrou do Orçamento Fiscal e da Seguridade Social para o Orçamento de Investimento das estatais e assumiu, assim, a condição de empresa estatal controlada independente. A principal implicação dessa mudança de paradigma consistiu na suspensão dos recebimentos de recursos financeiros do Tesouro Nacional para financiamento de despesas correntes.

Após adquirir a condição de independente, verificou-se que o Serpro recebeu autorização de alguns aportes de recursos, a saber: $\left(1^{\circ}\right)$ junho/2008 no valor de $R \$ 271$ milhões para aumento de capital (Lei n. 11.647, 2008); $\left(2^{\circ}\right)$ dezembro/2010 no valor de $\mathrm{R} \$ 250$ milhões (Medida Provisória n. 515, 2010), com repasse do financeiro parcelado em duas vezes:

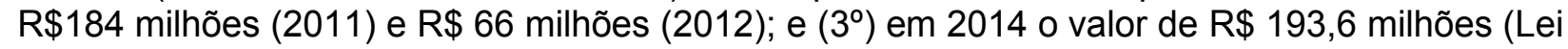
n. 12.942, 2013).

\subsection{Análise do saldo de caixa}

Considerando tais ocorrências durante o período em estudo (2005-2016), iniciou-se a análise observando-se a comportamento do saldo final de caixa, conforme Figura 1.

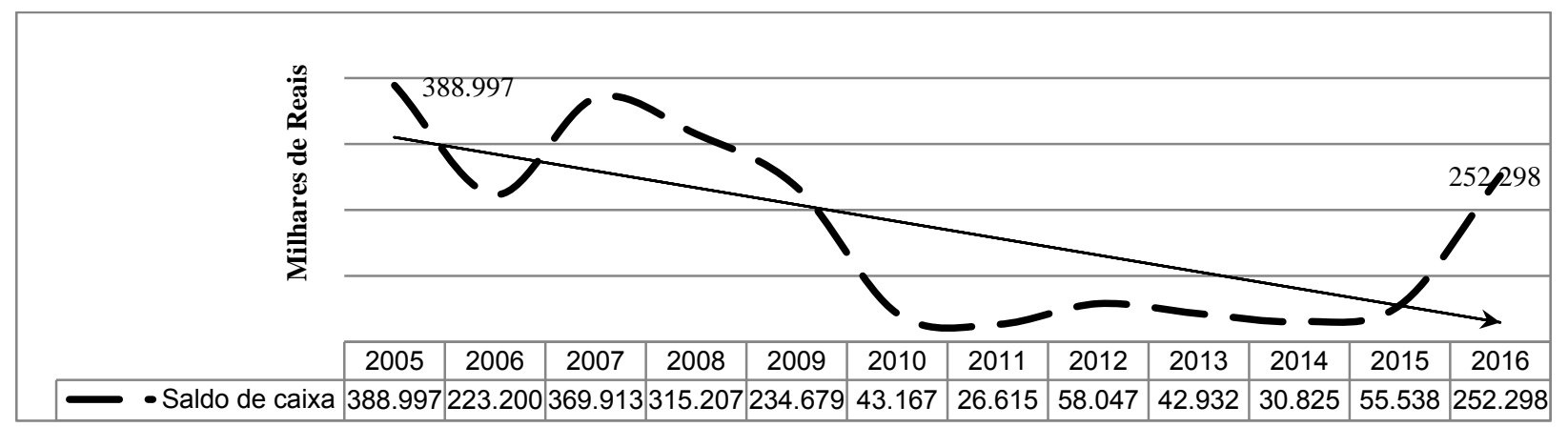

Figura 1. Evolução do saldo final de caixa no período de 2005-2016

Fonte: Dados da pesquisa (2017). 
Pode-se afirmar que, em 2005, o Serpro apresentava uma reserva de caixa considerável, tendo em vista a série que se segue para os saldos dessa rubrica. Entretanto, na Figura 1, demonstra-se acentuada redução do saldo final de caixa ao longo do período analisado, em especial até o ano de 2014. De um estoque de $R \$ 389$ milhões no fim do exercício 2005 - primeiro ano do Serpro como empresa independente - passa-se para $\mathrm{R} \$ 31$ milhões no final do exercício de 2014 , o que representa uma redução de $92 \%$, mesmo com os saldos alavancados pelos aportes ocorridos no período. Nos anos de 2015 e 2016, há uma recuperação do saldo de caixa, que se encerra $R$ \$ 55 e $R \$ 253$ milhões, respectivamente, mas ainda inferior ao início da série histórica. No período de 2005 a 2014, verifica-se que as injeções de recursos no Serpro via aumento de capital não foram suficientes às sucessivas reduções das disponibilidades. O aumento na necessidade de disponíveis demonstra possíveis sinais de ineficiência da geração interna de caixa na recomposição dos saldos utilizados.

Essa análise é corroborada pelo gráfico de tendência apresentado pela Figura 2, no qual evidencia-se o saldo final de caixa com e sem o efeito dos aportes, com o objetivo de se verificar, comparativamente, o desempenho financeiro. Em que pese as transferências dos recursos terem acontecido pontualmente nos exercícios de 2008, 2011, 2012 e 2014, optou-se pela média a fim de se ter uma tendência do efeito dos aportes no período (2008-2016). Tal procedimento justifica-se porque os saldos posteriores aos repasses estavam alavancados. Com esse procedimento, observa-se que os aportes corrigem uma situação de esgotamento total do caixa, alavancando a linha do saldo com aporte.

A partir de 2009, considerando a linha sem aporte (Figura 2), o resultado da análise passou a indicar situação deficitária, caso em que, se não houvesse a assistência da União, não haveria recursos financeiros para o pagamento das despesas operacionais comuns, como, por exemplo, despesas com pessoal, até o final do ano de 2015.

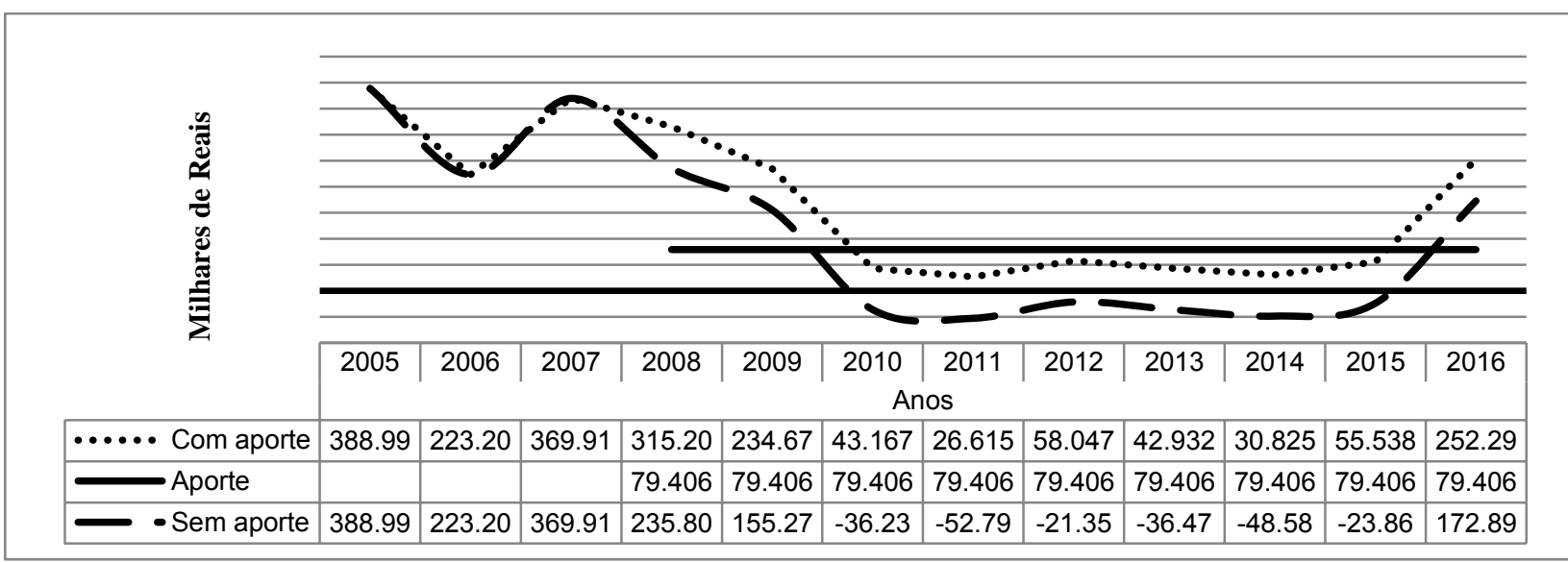

Figura 2. Evolução do saldo final de caixa no período de 2005-2016 com distribuição linear do aporte

Fonte: Dados da pesquisa (2017).

Para complementar essa análise precedente, a Tabela 3 demonstra um resumo do estoque do caixa, ano a ano, com os seus respectivos fluxos.

O primeiro aporte acontece no ano de 2008 , no valor de $\mathrm{R} \$ 271$ milhões. Nesse ano, ainda havia saldo de caixa inicial no valor de $\mathrm{R} \$ 369$ milhões e terminou com $\mathrm{R} \$ 315$ milhões, redução de $15 \%$. Excluindo pontualmente o valor do aporte, o saldo final de caixa seria de $\mathrm{R} \$$ 44 milhões, o qual não suportaria a demanda por caixa do exercício de 2009 , no valor de $\mathrm{R} \$ 80$ milhões (variação dos fluxos de caixa das atividades).

O saldo de caixa de 2010 transportado para 2011 foi R\$ 43 milhões. Observa-se no ano de 2011 que somente o déficit no FCO é maior que esse valor, esgotando, portanto, todo o saldo do estoque e ainda necessitando de $\mathrm{R} \$ 2$ milhões, que foi coberto pelo superávit do FCF, via aporte de capital. Em 2011, portanto, é possível indicar dependência do Serpro pela necessidade de recurso de aporte para pagar compromissos operacionais. 
Cabe informar que, conforme consta na DRE de 2010 e de 2011, o Serpro obteve dois prejuízos consecutivos de $\mathrm{R} \$ 176$ milhões e $\mathrm{R} \$ 175$ milhões, o que reforça a caracterização da situação deficitária da empresa e, por conseguinte, o aporte de capital para aumento de capital recebido nesse período tem natureza de subvenção econômica corrente, dado que destinada às necessidades de caixa e à amortização de déficits financeiros operacionais.

No campo legal, além da exigência de a transferência ser autorizada em lei específica, também há as implicações previstas na Lei de Diretrizes Orçamentárias (LDO). Como a transferência de recurso para o Serpro não se destina (a) a aumento de participação acionária, (b) fornecimento de bens ou prestação de serviço, (c) pagamento de empréstimo e financiamentos concedidos e (d) transferência para aplicação em programas de financiamento, que são as exceções previstas nas LDO's, o Serpro migraria do Orçamento de Investimento para o Fiscal, perdendo, com isso, a independência, e submetendo-se ao regime jurídico das empresas estatais dependentes. Acrescente-se que, nesse exercício de 2011, houve pagamento de dividendo no valor $\mathrm{R} \$ 40$ milhões e, dadas as razões já apresentadas, suscitam indícios de terem sido pagos com recursos aportados pela própria União.

Com relação a 2014, cabe o seguinte destaque: como o saldo de caixa no final de 2013 transportado para 2014 foi de R\$ 42 milhões, esse é o limite para um possível déficit na atividade de operacionais a ser demonstrado no $\mathrm{FCO}$, que foi ultrapassado em $\mathrm{R} \$ 65$ milhões (resultado do FCO de -108 milhões). Corroborando tal constatação, no orçamento de 2013 foi aprovado crédito especial no valor de $\mathrm{R} \$ 193,6$ milhões (Lei n. 12.942, 2013), em favor do Ministério da Fazenda, para realização de aporte de capital no Serpro, em 2014. Isto é, neste momento constata-se de forma cabal a necessidade de aportes de capital para o financiamento de suas atividades operacionais.

Somente a partir dos dados ora entabulados, constata-se a perda da independência do Serpro, haja vista que no exercício de 2012 a empresa recebeu a quantia de $\mathrm{R} \$ 66$ milhões e, em 2014, obteve recebimento de recursos financeiros com idêntica finalidade, a de financiar déficits recorrentes. Conforme art. $2^{\circ}$, inciso II, da Resolução do Senado Federal n. 43 (2001), tornar-se-ia uma empresa estatal dependente.

\section{Tabela 3}

\begin{tabular}{lrrrrrr} 
Demonstração dos fluxos de caixa composta com os saldos inicial e final \\
\hline Item & $\mathbf{2 0 0 5}$ & $\mathbf{2 0 0 6}$ & $\mathbf{2 0 0 7}$ & $\mathbf{2 0 0 8}$ & $\mathbf{2 0 0 9}$ & $\mathbf{2 0 1 0}$ \\
\hline Saldo inicial de caixa & 335.955 & 388.997 & 223.200 & 369.913 & 315,207 & 234.679 \\
FCO & 409.612 & 66.689 & 313.372 & -171.858 & 57.819 & -134.219 \\
FCl & -42.014 & -106.130 & -127.232 & -90.735 & -128.347 & -57.293 \\
FCF & -314.556 & -126.356 & -39.426 & 207.739 & -10.000 & 0 \\
Variação & 53.042 & -165.797 & 146.713 & -54.854 & -80.528 & -191.512 \\
Saldo outros bancos & & & & 147 & & \\
Saldo final caixa & $\mathbf{3 8 8 . 9 9 7}$ & $\mathbf{2 2 3 . 2 0 0}$ & $\mathbf{3 6 9 . 9 1 3}$ & $\mathbf{3 1 5 . 2 0 7}$ & $\mathbf{2 3 4 . 6 7 9}$ & $\mathbf{4 3 . 1 6 7}$ \\
\hline Item & $\mathbf{2 0 1 1}$ & $\mathbf{2 0 1 2}$ & $\mathbf{2 0 1 3}$ & $\mathbf{2 0 1 4}$ & $\mathbf{2 0 1 5}$ & $\mathbf{2 0 1 6}$ \\
\hline Saldo inicial de caixa & 43.167 & 26.615 & 58.047 & 42.932 & 30.825 & 55.538 \\
\hline FCO & -45.192 & 163.564 & 103.469 & -108.303 & 147.832 & 323.812 \\
\hline FCl & -115.252 & -198.132 & -118.584 & -97.454 & -123.119 & -127.052 \\
\hline FCF & 143.892 & 66.000 & 0 & 193.650 & - & - \\
\hline Variação & -16.552 & 31.432 & -15.115 & -12.107 & 24.713 & 196.760 \\
\hline Saldo outros bancos & & & & - & - & - \\
\hline Saldo final caixa & $\mathbf{2 6 . 6 1 5}$ & $\mathbf{5 8 . 0 4 7}$ & $\mathbf{4 2 . 9 3 2}$ & $\mathbf{3 0 . 8 2 5}$ & $\mathbf{5 5 . 5 3 8}$ & $\mathbf{2 5 2 . 2 9 8}$ \\
\hline Nal Varas & & & & & &
\end{tabular}

Nota. Valores em milhares de reais; Variação = saldo inicial de caixa + FCO + FCl + FCF.

FCO - Fluxo de caixa operacional

$\mathrm{FCl}$ - Fluxo de caixa de investimentos

FCF - Fluxo de caixa de financiamento

Fonte: Dados da pesquisa (2017).

Em resumo, para a análise dos saldos de caixa, não se pode afirmar que em todos os anos em que ocorreu déficit no FCO haja indícios de possível situação de fragilidade da condição de independência do Serpro, dado que esses déficits poderiam ser financiados com estoque de caixa dos anos anteriores. Porém, com relação aos exercícios de 2011, 2013 e 2014, há indícios. Em 2011, porque o estoque de caixa transportado não foi suficiente à cobertura do déficit operacional, restando à administração recorrer a recurso do aporte para 
cobrir a diferença, ou seja, o Serpro pagou com recursos do aporte de capital de 2011 despesas operacionais correntes (ou despesas de custeio). Em 2013 e 2014, porque incide na hipótese direta de dependência estabelecida pela Resolução do Senado Federal n. 43 (2001). Isso quer dizer que a recepção de recursos da União como aporte para aumento de capital, nesse nível de déficit em que se encontrava o Serpro, não foi aderente ao regulamentado no normativo pertinente.

\subsection{Análise horizontal dos fluxos das atividades - operacional, de investimento e de financiamento}

$\mathrm{Na}$ Tabela 4, a seguir, demonstra-se a capacidade dos recursos gerados pelo FCO para, no mínimo, manter o nível potencial de produção dos equipamentos e instalações da atual capacidade instalada da empresa.

Tabela 4

FCO descontado dos recursos financeiros reservados para a depreciação (em milhares de reais)

\begin{tabular}{lrrrrrr}
\hline Item & $\mathbf{2 0 0 6}$ & $\mathbf{2 0 0 7}$ & $\mathbf{2 0 0 8}$ & $\mathbf{2 0 0 9}$ & $\mathbf{2 0 1 0}$ & $\mathbf{2 0 1 1}$ \\
\hline (a) FCO & 66.689 & 313,372 & -171.858 & 57.819 & -134.219 & -45.192 \\
\hline (b) Depreciação/Amortização & -53.166 & -73.863 & -93.692 & -102.124 & -110.563 & -133.610 \\
\hline (c) = (a) - (b) FCO livre & 13.523 & 239.509 & -265.550 & -44.304 & -244.782 & -178.803 \\
\hline Item & $\mathbf{2 0 1 2}$ & $\mathbf{2 0 1 3}$ & $\mathbf{2 0 1 4}$ & $\mathbf{2 0 1 5}$ & $\mathbf{2 0 1 6}$ & \\
\hline (a) FCO & 163.564 & 103.469 & -108.303 & 147.832 & 323.812 \\
\hline (b) Depreciação/Amortização & -108.829 & -120.835 & -133.495 & -39.995 & -44.719 \\
\hline (c) = (a) - (b) FCO livre & 54.735 & -17.366 & -241.797 & 107.837 & 279.093 & \\
\hline
\end{tabular}

Nota. FCO - Fluxo de caixa operacional

Fonte: Dados da pesquisa (2017).

Como se observa, no período de 2008 a 2011, e também nos anos de 2013 e 2014, as atividades operacionais não foram capazes de gerar caixa suficiente para manter a atual capacidade instalada do Serpro. Nesses exercícios, a reposição do imobilizado e do intangível foi arcada com recursos do aporte realizado pelo controlador.

Outra informação importante a ser observada por meio da Tabela 4 é a instabilidade do FCO, que pode ser um indicativo ou de que os recursos não foram investidos de forma eficiente e, por isso, não estão gerando caixa operacional suficiente, ou de inadimplência dos principais clientes. Comparando o comportamento do FCO com o critério apresentado por Almeida (2000), o Serpro se enquadraria na primeira situação (ver Tabela 1), nos estágios iniciais de sua vida, em que é comum a recorrência de FCO negativo ou pouco expressivo com relação aos investimentos. Essa situação incorreu em 6 dos últimos 11 anos analisados, com uma persistência no período de 2008 a 2011.

A Tabela 5 apresenta o fluxo das atividades de investimento do Serpro comparado com a depreciação/amortização do período, e tem como objetivo possibilitar a avaliação da política de investimento da empresa. Se o $\mathrm{FCl}$ estiver próximo à depreciação/amortização significa que a empresa está investindo para manter a sua capacidade instalada. Não se avalia quem pagará o investimento, se mediante recursos das operações ou mediante recursos do controlador, mas qual é a magnitude do investimento e se ele está, ao menos, repondo as condições correntes para não haver descontinuidade.

Tabela 5

Demonstrativo de expansão/contração dos investimentos (em milhares de reais)

\begin{tabular}{lrrrrrr}
\hline Item & $\mathbf{2 0 0 6}$ & $\mathbf{2 0 0 7}$ & $\mathbf{2 0 0 8}$ & $\mathbf{2 0 0 9}$ & $\mathbf{2 0 1 0}$ & $\mathbf{2 0 1 1}$ \\
\hline (a) FCl - Fluxo de caixa de investimentos & 106.130 & 127.232 & 90,735 & 128,347 & 57,293 & 115,252 \\
(b) Depreciação/Amortização & 53.166 & 73.863 & 93.692 & 102.124 & 110,563 & 133,610 \\
(c=a-b) Expansão/contração & 52.965 & 53.369 & -2.957 & 26.223 & -53.270 & -18.359 \\
\hline Item & $\mathbf{2 0 1 2}$ & $\mathbf{2 0 1 3}$ & $\mathbf{2 0 1 4}$ & $\mathbf{2 0 1 5}$ & $\mathbf{2 0 1 6}$ \\
\hline (a) FCl - Fluxo de caixa de investimentos & 198.132 & 118.584 & 97.454 & 123.119 & 127.052 \\
\hline (b) Depreciação/Amortização & 108.829 & 120.835 & 133.495 & 39.995 & 44.719 \\
\hline (c=a-b) Expansão/contração & 89.303 & -2.251 & -36.041 & 83.124 & 82.333 \\
\hline
\end{tabular}

Nota. Fonte: Dados da pesquisa (2017). 
Conforme se observa na Tabela 5 , em todo período analisado, o $\mathrm{FCl}$ foi consumidor de recursos e, pelas informações constantes da DFC e das Notas Explicativas, os investimentos são direcionados basicamente para o imobilizado e o intangível. Verificam-se sinais de expansão da capacidade instalada nos exercícios de 2006, 2007, 2009, 2012, 2015 e 2016. Nesses exercícios, o consumo de recursos na atividade de investimento foi superior ao valor da depreciação somada à amortização. Indica que os investimentos ultrapassaram o necessário para manter a capacidade instalada. Nos demais exercícios, houve sinais de contração da capacidade instalada, devido à retração nos investimentos abaixo do necessário à reposição.

Em outras palavras, apesar de o $\mathrm{FCl}$ ter sido negativo, indicando que recursos foram direcionados para imobilizado e intangível, os retornos (desse investimento) não contribuem para geração suficiente de $\mathrm{FCO}$, ou seja, os ativos objetos dos investimentos ainda não demonstraram ganho de eficiência na capacidade de produção. Diante de tal cenário, há indício de que a causa da retração nos investimentos está vinculada a alguma incapacidade de o Serpro gerar superávits operacionais, dado que nos exercícios de retração (exceto 2013) também houve déficit no FCO. Percebe-se, então, que o FCO "concorreu" com o $\mathrm{FCl}$ pelas sobras do FCF ou dos estoques de caixa da empresa.

A insuficiente geração de caixa operacional observada em vários exercícios do período analisado, combinada com as recorrentes demandas de recursos nas atividades de investimento, justifica a ocorrência de fluxos de caixa superavitário das atividades de financiamento superavitários, que passaram a ser importante fonte de recursos para o caixa da empresa, inclusive para cobrir gastos operacionais.

Em relação ao fluxo com os sócios, analisando o período em que o Serpro pagou dividendos e juros sobre capital próprio (2005 a 2011), foi pago o total de $R \$ 275$ milhões (vide Tabela 6), enquanto nesse período foram recebidos três aportes que totalizaram $R \$ 521$ milhões.

Tabela 6

\begin{tabular}{llllllll} 
Histórico de remuneração do sócio de 2005-2011 & (em milhares de reais) & \\
\hline Item & $\mathbf{2 0 0 5}$ & $\mathbf{2 0 0 6}$ & $\mathbf{2 0 0 7}$ & $\mathbf{2 0 0 8}$ & $\mathbf{2 0 0 9}$ & $\mathbf{2 0 1 1}$ & Total \\
\hline Distribuição de Dividendos Ordinários & 20,494 & 41,321 & 29,414 & 56,966 & 10,000 & 40,108 & 198,303 \\
Distribução de Dividendos Complementares & 19,460 & 21,020 & - & - & - & - & 40,480 \\
Juros sobre capital próprio & - & - & 25,000 & - & 10,905 & - & 35,905 \\
Dividendos + Juros sobre capital próprio & 39,954 & 62,342 & 54,414 & 56,966 & 20,905 & 40,108 & 274,688 \\
\hline
\end{tabular}

Nota. Fonte: Dados da pesquisa (2017).

Conforme mencionado, nos anos de 2008, 2010 e 2011, as atividades operacionais geraram FCO negativo e, mesmo em tal situação, o Serpro distribuiu dividendos e/ou juros sobre capital próprio nos respectivos exercícios. Em razão disso, pode-se inferir que os recursos dos aportes de capital também foram usados para remunerar os sócios.

Analisando conjuntamente os três fluxos de caixa - FCO, FCl e FCF - acumulados em toda série histórica, observa-se o seguinte perfil de geração de caixa, em termos nominais: (1) o FCO gerou caixa no valor de R\$ 1.126 milhões, com a presença de déficit em quatro exercícios (2008, 2010, 2011 e 2014); (2) o $\mathrm{FCl}$ consumiu caixa no valor $\mathrm{R} \$ 1.331$ milhões, com a ocorrência de desinvestimento em alguns deles; (3) o FCF representa um aporte de R\$ 120 milhões, que, somado ao $\mathrm{FCO}$ gerado no período e subtraído do $\mathrm{FCl}$, representa um déficit líquido de $\mathrm{R} \$ 85$ milhões em 11 anos.

Em resumo, como a geração de caixa operacional foi insuficiente face ao consumo de caixa nas outras atividades, a empresa recorreu a recursos de aporte da União e ao saldo de caixa de anos anteriores. Essa insuficiência poderia ter resultado em insolvência, caso a União não tivesse aportado recursos. Especificamente, para liquidar suas obrigações, o Serpro recorreu não só aos recursos financeiros de terceiros, mas também a recorrentes aportes do controlador ( $R \$ 714,6$ milhões).

Em resumo, a análise horizontal dos FCO, FCl e FCF possibilitou verificar que a empresa não obteve capacidade de autofinanciamento, e que, para continuar as operações, recorreu a auxílio do controlador que aportou recursos para aumento de capital. Mas, conforme demonstrado, uma vez que a empresa encontrava-se em situação deficitária, à luz da essência 
sobre a forma, os recursos deveriam ser recepcionados e reconhecidos contabilmente como subvenção. Consequentemente, o Serpro não atendeu aos requisitos legais de modo a manter as características necessárias de uma empresa estatal independente no período de 2005 a 2016.

Importante destacar que a afirmação ora efetuada é feita considerando as limitações quanto aos procedimentos metodológicos adotados, seja no que tange à escolha dos indicadores ora utilizados, seja pelo fato de se obter informações na condição de usuário externo, fazendo com que dados internos que poderiam revelar um outro cenário não fossem analisados. Destaca-se, também, as limitações do tipo de análise e de pesquisa realizados natureza qualitativa e do tipo documental.

\subsection{Análise dos indicadores}

Os resultados apresentados na análise horizontal são corroborados pela análise de indicadores, demonstrados na Tabela 7, conforme categorias - respectivamente, de liquidez, de investimento e de retorno para o período 2005-2016.

Tabela 7

\begin{tabular}{|c|c|c|c|c|c|c|}
\hline Indicadores & 2005 & 2006 & 2007 & 2008 & 2009 & 2010 \\
\hline Cobertura de dívidas com caixa & 1,23 & 0,01 & 0,82 & $-0,64$ & 0,08 & $-0,27$ \\
\hline Cobertura de dividendos com caixa & 10,25 & 1,07 & 5,76 & $-3,02$ & 2,77 & - \\
\hline Investimento/financiamento & 0,13 & 0,84 & 3,23 & $-0,44$ & 12,83 & - \\
\hline Cobertura dos investimentos & 9,75 & 0,63 & 2,46 & $-1,89$ & 0,45 & $-2,34$ \\
\hline Retorno Total & 1,15 & 0,29 & 1,88 & $-1,47$ & 0,42 & $-2,34$ \\
\hline Retorno sobre o Lucro & 3,73 & 0,42 & 3,26 & $-237,73$ & 1,34 & 0,77 \\
\hline Qualidade do resultado & 2,32 & 0,23 & 2,00 & $-3,66$ & 0,79 & 0,47 \\
\hline Retorno sobre o patrimônio líquido & 0,69 & 0,10 & 0,42 & $-0,17$ & 0,06 & $-0,16$ \\
\hline Retorno sobre imobilizado + intangível & 1,15 & 0,15 & 0,60 & $-0,32$ & 0,10 & $-0,22$ \\
\hline Indicadores & 2011 & 2,12 & 2013 & 2014 & 2015 & 2016 \\
\hline Cobertura de dívidas com caixa & $-0,18$ & 0,30 & 0,16 & $-0,16$ & 0,19 & 0,40 \\
\hline Cobertura de dividendos com caixa & $-1,13$ & - & - & - & - & - \\
\hline Investimento/financiamento & $-0,80$ & $-3,00$ & - & $-0,50$ & - & \\
\hline Cobertura dos investimentos & $-0,39$ & 0,83 & 0,87 & $-1,11$ & 1,20 & 2,55 \\
\hline Retorno Total & $-1,58$ & 1,24 & 0,87 & $-0,37$ & 1,20 & 2,55 \\
\hline Retorno sobre o Lucro & 0,26 & 2,48 & 2,21 & $-6,68$ & $-0,42$ & $-2,00$ \\
\hline Qualidade do resultado & 0,32 & 1,21 & 0,55 & $-1,40$ & $-0,34$ & $-1,78$ \\
\hline Retorno sobre o patrimônio líquido & $-0,05$ & 0,16 & 0,10 & $-0,08$ & 0,18 & 0,79 \\
\hline Retorno sobre imobilizado + intangível & $-0,09$ & 0,27 & 0,16 & $-0,16$ & 0,23 & 0,66 \\
\hline
\end{tabular}

Nota. Fonte: Dados da pesquisa (2017).

A partir dos índices de liquidez, constatou-se que o Serpro encontrou dificuldades para o pagamento das suas dívidas de curto prazo, uma vez que, à exceção do exercício de 2005, no qual para cada $R \$ 1,00$ de dívida a atividade operacional livre gerou $R \$ 1,23$, o indicador de cobertura de dívidas com caixa demonstrou resultado de baixa liquidez. Observa-se que o motivo para os resultados negativos desse indicador nos exercícios de 2008, 2010, 2011 e 2014 deu-se em razão dos déficits operacionais ocorridos nesses anos. Ficou demonstrado que, além de não gerar recursos para pagar parcelas das dívidas de curto prazo, ainda aumentou a demanda por aporte de capital do controlador. Outro fato a ser ressaltado é que, somente nos exercícios de 2005 (1,25), $2007(0,82)$ e $2016(0,40)$, esse indicador atingiu o patamar considerado adequado (igual ou superior a 0,4) para empresas saudáveis, segundo Casezy e Bartzcak (1984, como citado em Almeida, 2000). Esses resultados sinalizam que a empresa enfrenta dificuldades de gerar caixa pelas operações para honrar as dívidas financeiras captadas.

Em relação aos dividendos, nos exercícios de 2010 e de 2012 a 2016, não houve pagamento - índice de cobertura de dividendos de caixa nulo. Nos outros exercícios, apesar dos déficits no FCO, houve pagamento em 2008 e 2011. Com relação a 2008, os dividendos podem ter sido pagos com recursos de aporte de capital. No entanto, com relação a 2011, a possibilidade de os dividendos terem sido pagos com aporte torna-se mais evidente, dado que o saldo anterior de caixa de 2010 (R\$ 43 milhões) transferido para 2011 foi inferior ao déficit 
operacional ( $R \$ 45$ milhões). Portanto, tanto a parcela descoberta do déficit $(R \$ 43-R \$ 45)$ quanto os dividendos utilizaram-se do superávit gerado na atividade de financiamento, decorrente de aporte do controlador.

Quanto aos indicadores de investimento, observa-se uma acentuada variação. $O$ índice de investimento/financiamento apresentou resultados negativos nos exercícios de $2008(-0,44)$, $2011(-0,80), 2012(-3,00)$ e $2014(-0,50)$. Demonstra que a atividade de financiamento contribuiu com os pagamentos dos investimentos, via aumento de capital. Ressalta que, nos dois primeiros anos, o financiamento cobriu totalmente os investimentos e ainda sobraram recursos, que foram utilizados para consumos ordinários/correntes - das atividades operacionais. Nos anos de 2005 (0,13), $2006(0,84), 2007(3,23)$ e $2009(12,83)$, o FCl foi deficitário. Nos anos, 2010, 2013, 2015 e 2016 não houve movimentação no fluxo.

Com relação aos indicadores de retorno, observa-se um distanciamento do índice retorno sobre o lucro com relação ao de qualidade do resultado. A razão para isso está no fato de o índice de qualidade sobre o resultado desconsiderar o efeito de itens que não afetam as disponibilidades, como os juros, impostos e a depreciação, o que resulta em uma melhor aproximação do caixa aos resultados (Braga \& Marques, 2001). Com relação ao índice retorno sobre o lucro, além de alguns resultados elevados, destacam-se suas oscilações. Os exercícios de 2005 (3,73), 2007 (3,26), 2009 (1,34), 2012 (2,48) e 2013 (2,21) apresentam resultados positivos elevados, enquanto que em 2006 (0,42), $2008(-237,73), 2010(0,77), 2011$ $(0,26), 2014(-6,68), 2015(-0,42)$ e $2016(-2,00)$ ocorre o oposto. Pode significar recebimento de dívidas de períodos anteriores ou reflexo do impacto de registros acentuados de provisões, créditos fiscais diferidos, entre outros.

$\mathrm{Na}$ maioria dos anos em estudo, o indicador qualidade do resultado, diferentemente do retorno sobre o lucro, apresenta baixa conversão do lucro em caixa. Embora o indicador de qualidade do resultado tenha demonstrado que o resultado operacional gerou caixa nos exercícios de $2006(0,23), 2009(0,79)$ e $2013(0,55)$, observa-se que somente em $2005(2,32)$ e $2007(2,00)$ esses valores são relevantes, o que demonstra baixa qualidade do resultado gerado. No exercício de 2008 o FCO foi negativo e, em 2010 e 2011, tanto o lucro antes de juros e imposto quanto o FCO foram negativos, o que justifica a baixa qualidade do resultado gerado.

O indicador de retorno total, que mede o nível de geração interna de recurso no Serpro para aplicação nas suas atividades de investimento e financiamento, apresentou como melhor desempenho os resultados de $2005(1,15), 2007(1,88)$ e $2012(1,24)$. Nos demais anos, o indicador revela inversão do fluxo, com a atividade financiamento cobrindo a insuficiência da atividade operacional.

O retorno sobre o imobilizado e o intangível, pelo fato de a empresa apresentar FCO negativo em 2008, 2010, 2011, 2015 e 2016, também ficou negativo nesses exercícios e indica que em nada contribui com os investimentos. Em 2005, aconteceu o maior retorno, e gerou $\mathrm{R} \$ 1,15$ pelo $\mathrm{FCO}$ para cada $\mathrm{R} \$ 1,00$ investido na expansão da capacidade de produção. Nos demais exercícios, o índice retorno sobre o imobilizado e intangível está abaixo de 1, o que indica a possibilidade de as decisões de investimento, evidenciadas a partir do $\mathrm{FCl}$, não terem sido adequadas.

Em resumo, os resultados da análise dos indicadores sinalizaram uma posição de baixa liquidez e qualidade dos resultados, bem como ineficientes retornos sobre os investimentos para o Serpro, no período estudado. Em sua maioria, conforme exposição, os indicadores demonstraram a necessidade de se recorrer a aporte de capital para pagamento de dívidas. Constatou-se, no período analisado, que o Serpro, em 2006 - segundo ano de independência - apresentava evolução de dependência, sinalizada pela variação líquida negativa de caixa (R\$ 165 milhões) e queda no valor FCO. Essa tendência permaneceu nos anos seguintes, apresentando: (1) queda acentuada no estoque de caixa $R \$ 388$ (2005) para $R \$ 43$ (2013), apesar dos aportes; (2) insuficiência das atividades operacionais - sem aporte, a partir de 2010, haveria dificuldade de liquidez; (3) indícios de inadequação nos investimentos - FCO recorrentemente negativo; (4) FCF recorrentemente positivo, financiando, inclusive, atividades operacionais; (5) saldo de caixa transportado para 2011 inferior ao déficit operacional e (6) queda acentuada nos índices de liquidez e os índices de investimento, confirmando que o 
financiamento cobre as atividades de investimento e operacional, como já evidenciado na análise horizontal.

Do ponto de vista do cumprimento das formalidades exigidas nas transações com aporte de capital, constatou-se descumprimento da Resolução do Senado Federal n. 43 (2001), dado que, permanecendo como independente, o Serpro recebeu recurso financeiro da União no exercício de 2012 e obteve previsão orçamentária no exercício 2013 com aporte em 2014, o que caracteriza dependência.

Por fim, é possível destacar dois pontos finais a partir da análise. O primeiro refere-se à necessidade de se rever o reconhecimento dos aportes de capital no ente controlador nos períodos em que as transferências aconteceram para, materialmente, cobrir déficit financeiro do Serpro. Como o recurso foi formalmente encaminhado para aumento de capital, a contrapartida do caixa, no ente controlador, foi o investimento, quando, à luz da essência sobre a forma, a contrapartida deveria ser em despesa efetiva, alterando o patrimônio líquido. $O$ segundo é relativo à necessidade de refletir a situação à exigência de lei específica para autorizar a subvenção, como definido na Constituição da República Federativa do Brasil (1988). e na Lei Complementar n. 101 (2000).

\section{CONCLUSÃO}

O estudo objetivou analisar se o Serpro deveria ter permanecido como empresa estatal independente no período de 2005 a 2016, tendo em vista as características e os requisitos para essa condição. A partir do normativo legal, bem como da análise horizontal e de indicadores, pôde-se afirmar a existência de indícios de possíveis condições de dependência do Serpro a recursos da União, para financiar despesas correntes, o que indica situação de não aderência ao arcabouço regulamentador das características e dos requisitos necessários para uma empresa estatal enquadrar-se como independente.

Especificamente, o estudo analisou o comportamento do estoque de caixa abordandose os fluxos das atividades operacionais, de investimentos e financiamentos. A análise em perspectiva dos saldos de caixa evidenciou incapacidade dos ativos operacionais de manter ou produzir novos estoques de caixa. O caixa, de um estoque de $\mathrm{R} \$ 388$ milhões no fim do exercício 2005 - primeiro ano do Serpro como empresa independente -, passou para $\mathrm{R} \$ 31$ milhões no final do exercício de 2014 , o que representa uma redução de $92 \%$, mesmo com os saldos alavancados pelos aportes ocorridos no período. Nos anos subsequentes (2015 e 2016) houve certa recuperação do saldo, contudo, ainda, abaixo do saldo do início da série histórica (252 milhões), quadro esse agravado se for considerado os aportes realizados no montante de $\mathrm{R} \$ 715$ milhões (déficit de caixa líquido acumulado no período de $\mathrm{R} \$ 798$ milhões).

A razão para tal desempenho foi explicada na análise dos fluxos e reafirmada nos resultados dos indicadores de liquidez, investimento e retorno. O conjunto dessas análises demonstrou a insuficiência das atividades operacionais, dadas as ausências de condições de gerar superávits suficientes para cobertura dos investimentos, levando a estatal independente à recorrente assistência da União.

Com base na evidência de que o saldo de caixa de 2010, transportado para 2011, não ter sido suficiente para cobrir nem mesmo o déficit operacional de 2011, ficaram caracterizados os indícios necessários de que o Serpro encontrava-se em situação financeira deficitária e que qualquer assistência da União seria, materialmente e à luz da essência sobre a forma, uma subvenção econômica para financiamento de despesas correntes. Soma-se ao indício, o fato de receber recurso financeiro em 2012 e 2014. Isso posto, sinaliza, portanto, que o Serpro, em 2011, 2013 e 2014, não mais reunia as características e os requisitos necessários para manterse como empresa controlada estatal independente, conforme definido na Lei Complementar $\mathrm{n}$. 101 (2000) e na Resolução do Senado Federal n. 43 (2001). Já em relação aos anos de 2015 e 2016, embora tenha gerado FCO positivo, sob a ótica econômica apresenta acentuados prejuízos (2015 = R \$ 356 milhões; $2016=\mathrm{R} \$ 162$ milhões) e redução de seu patrimônio líquido (2015 = R\$ 804 milhões; $2016=\mathrm{R} \$ 410$ milhões).

Ressalta-se, por fim, que os resultados descritos estão limitados ao objeto de análise. Não podem ser extrapolado às outras empresas estatais independentes. Também as 
limitações inerentes da pesquisa, em especial pelo não ajuste dos indicadores à inflação do período. Para continuidade em pesquisas futuras, sugere-se empregar a metodologia ora proposta com a utilização dos dados contábeis ajustados pela inflação, a fim de identificar até que ponto as conclusões ora evidenciadas poderiam ser alteradas ou ratificadas, bem como o uso dessa metodologia para outras empresas, a fim de validar ou não o emprego de tais indicadores para análise de independência. Como alternativa, sugere-se verificar a aplicabilidade do indicador proposto por Fernandes e Meireles (2013), com fins de avaliar a ocorrência de um possível déficit econômico do Serpro.

\section{REFERÊNCIAS}

Almeida, R. S. G. D. (2000). Análise da demonstração dos fluxos de caixa. UNB Contábil, 3(2), 105-144.

Aslan, H., \& Kumar, P. (2012). Strategic Ownership Structure and the Cost of Debt. Review of Financial Studies, 25(7), 2257-2299.

Andrade, C. A. S. (2012). O controle do endividamento público e a autonomia dos entes da federação. 219 f. Dissertação (Mestrado) - Faculdade de Direito da Universidade de São Paulo, São Paulo.

Azevedo, R. R. (2013). Uma análise dos índices da lei de responsabilidade fiscal nos municípios paulistas após a implantação do projeto AUDESP. Revista de Gestão, Finanças e Contabilidade, 3(2), 39.

Azevedo, R. R. (2016). Resistência ao planejamento de resultados e a lógica orçamentária dominante em municípios. 210 f. Tese de Doutorado, Faculdade de Economia, Administração e Contabilidade, Universidade de São Paulo, Ribeirão Preto, São Paulo, Brasil.

Bachmann, R. K. B., da Fonseca Tonin, J. M., Colauto, R. D., \& Scherer, L. M. (2014). Reflexos do desempenho financeiro nas boas notícias: análise linguística em companhias brasileiras transparentes. Revista Contemporânea de Contabilidade, 11(22), 49-72.

Braga, R., \& Marques, J. A. V. D. C. (2001). Avaliação da liquidez das empresas através da análise da demonstração de fluxos de caixa. Revista Contabilidade \& Finanças, 12(25), 06-23.

Comitê de Pronunciamentos Contábeis. (2010). Pronunciamento Técnico CPC 03 (R2): Demonstração dos Fluxos de Caixa. Brasília: CPC.

Constituição da República Federativa do Brasil. (1988). Recuperado em 15 de outubro, 2014, de: http://www.planalto.gov.br/ccivil_03/constituicao/Constituicaocompilado.htm

Fernandes, M. de A., \& Meireles, M. (2013). Justificativa e proposta de indicador de sustentabilidade financeira. Revista Contemporânea de Contabilidade, 10(20), 75-96.

Gerigk, W., Clemente, A., \& Ribeiro, F. (2014). O padrão do endividamento público nos municípios brasileiros de porte médio após a lei de responsabilidade fiscal. Revista Ambiente Contábil, 6(1), 122.

Hatadani, A. A. M. (2015). O processo de controle de concessão de créditos adicionais para empresas estatais dependentes: um estudo de caso. Trabalho de conclusão de curso de Graduação, Universidade Federal de Lavras, Lavras.

Lei Complementar n. 101, de 04 de maio de 2000 (2000). Estabelece normas de finanças públicas voltadas para a responsabilidade na gestão fiscal e dá outras providências. Recuperado em 15 de outubro, 2015, de http://www.planalto.gov.br/ccivil_03/LEIS/LCP/Lcp101.htm

Lei n. 12.942, de 27 de dezembro de 2013 (2013). Abre ao Orçamento Fiscal da União, em favor dos Ministérios da Fazenda e do Turismo e de Encargos Financeiros da União, 
crédito especial no valor de $\mathrm{R} \$ 367.260 .302,00$, para os fins que especifica. Recuperado em 20 de junho, 2015, de http://www.planalto.gov.br/ccivil_03/_Ato20112014/2013/Lei/L12942.htm.

Lei n. 4.320, de 17 de março de 1964 (1964). Estatui normas gerais de direito financeiro para elaboração e controle dos orçamentos e balanços da União, dos Estados, dos Municípios e do Distrito Federal. Recuperado em 15 de outubro, 2015, de http://www.planalto.gov.br/ccivil_03/LEIS/L4320.htm

Lei n. 4.516, de 1 de dezembro de 1964 (1964). Cria o Serviço Federal de Processamento de Dados, vinculados ao Ministério da Fazenda. Recuperado em 20 de junho, 2015, dehttp://www.planalto.gov.br/ccivil_03/leis/L4516.htm

Lei n. 5.615, de 13 de outubro de 1970 (1970). Dispõe sobre o Serviço Federal de Processamento de Dados (SERPRO) e dá outras providências. Recuperado em 02 de outubro, 2015, de http://www.planalto.gov.br/ccivil_03/leis/L5615.htm

Lei n. 6.404, de 15 de dezembro de 1976 (1976). Dispõe sobre as Sociedades por Ações. $\begin{array}{lllll}\text { Recuperado em } 15 \text { de } & \text { outubro, }\end{array}$ http://www.planalto.gov.br/ccivil_03/leis/l6404.htm

Lei n. 11.647, de 24 de março de 2008 (2008). Estima a receita e fixa a despesa da União para o exercício financeiro de 2008. Recuperado em 05 de outubro, 2015, de http://www.planalto.gov.br/ccivil_03/_ato2007-2010/2008/Lei/L11647.htm

Linhares, F., Penna, C., \& Borges, G. (2013). Os efeitos da Lei de Responsabilidade Fiscal no endividamento dos municípios do Piauí. Revista de Administração Pública, 47(6), 13591374.

Mamede, S. P. N., Nakamura, W. T., Nakamura, E. A. M. V., Jones, G. D. C., \& Jardim, J. R. P. S. (2017). Empresas brasileiras estatais e não estatais: uma análise das relações de endividamento. Revista Evidenciação Contábil \& Finanças, 5(2), 4-22.

Medida provisória n. 515, de 28 de dezembro de 2010 (2010). Abre crédito extraordinário em favor da Justiça do Trabalho e de diversos órgãos do Poder Executivo, no valor global de $\mathrm{R} \$$ 26.673.264.196,00, para os fins que especifica. Recuperado em 20 de junho, 2015, de http://www.planalto.gov.br/ccivil_03/_Ato2007-2010/2010/Mpv/515.htm.

Mello, G. R., \& Dalchiavon, E. C. (2012). A lei de responsabilidade fiscal (LRF) e o impacto sobre o endividamento dos municípios potiguares. Contextus, 10(2).

Nisiyama, E. K., \& Nakamura, W. T. (2015). Pesquisas internacionais recentes em estrutura de capital. Revista de Administração de Roraima, Brasil, 5(1).

Portaria Interministerial da Secretaria do Tesouro Nacional e Secretaria de Orçamento Federal $n^{\circ}$ 163, de 4 de maio de 2001. (2001). Dispõe sobre normas gerais de consolidação das Contas Públicas no âmbito da União, Estados, Distrito Federal e Municípios, e dá outras providências. Recuperado em 02 de setembro, 2014, de http://www3.tesouro.fazenda.gov.br/legislacao/download/contabilidade/Portaria_Interm_1 63_2001_Atualizada_2011_23DEZ2011.pdf

Portaria n. 589 da Secretaria do Tesouro Nacional, de 27 de dezembro de 2001. (2001). Estabelece conceitos, regras e procedimentos contábeis para consolidação das empresas estatais dependentes nas contas públicas e dá outras providências. $\begin{array}{llllll}\text { Recuperado em } 02 \text { de } & \text { setembro, }\end{array}$ http://www3.tesouro.gov.br/legislacao/download/contabilidade/Port_589_2001.pdf

Quintana, A. C., Porto, J. A., \& Lemos, S. W. (2008). Análise financeira das empresas de telefonia fixa por meio da aplicação de índices de liquidez nas demonstrações dos fluxos de caixa. Revista Contemporânea de Contabilidade, 1(10), 91-100.

Resolução do Senado Federal n 43, 26 de dezembro de 2001. (2001). Dispõe sobre as operações de crédito interno e externo dos Estados, do Distrito Federal e dos Municípios, 
inclusive concessão de garantias, seus limites e condições de autorização, e dá outras providências. Recuperado em 02 de setembro, 2014, de http://legis.senado.gov.br/legislacao/ListaPublicacoes.action?id=234195\&tipoDocumento= RSF\&tipoTexto=PUB.

Santos, S. R. T., \& Alves, T. W. (2011). O impacto da Lei de Responsabilidade Fiscal no desempenho financeiro e na execução orçamentária dos municípios no Rio Grande do Sul de 1997 a 2004. Revista de Administração Pública, 45(1), 181-208.

Sun, J., Ding, L., Guo, J. M., \& Li, Y. (2016). Ownership, capital structure and financing decision: evidence from the UK. The British Accounting Review, 1-16. 